\title{
THE ENCORE PROJECT: SUSTAINABLE SOLUTIONS FOR CEMENTITIOUS MATERIALS
}

Enzo Martinelli, Joaquim A.O. Barros, Guillermo Etse, Liberato Ferrara, Paula C. Folino, Eduardus A.B. Koenders, and Romildo D. Toledo Filho

Synopsis: Since concrete is the most widely utilized construction material, several solutions are currently being developed and investigated for enhancing the sustainability of cementitious materials. One of these solutions is based on producing Recycled Concrete Aggregates (RCA) from existing concrete members resulting by either industrial processes or demolitions of existing structures as a whole. Moreover, waste resulting from industrial processes other than the building construction (i.e., tire recycling, production of steel, powders resulting from other depuration processes) are also being considered as possible low-impact constituents for producing structural concrete and Fiber-Reinforced Cementitious Composites (FRCC). Furthermore, the use of natural fibers is another option for producing environmentally-friendly and cost-effective materials, depending on the local availability of raw materials. To promote the use of concretes partially composed of recycled constituents, their influence on the mechanical and durability performance of these concretes have to be deeply investigated and correlated. This was the main goal of the EnCoRe Project (www.encore-fp7.unisa.it), a EU-funded initiative, whose activities and main findings are summarized in this paper.

Keywords: Concrete, Sustainability, Recycled aggregates, Cement replacements, Recycled Fibers, Natural Fibers, Compressive strength, Post-cracking behavior, Self-healing capability. 
Biography: Enzo Martinelli is an Associate Professor in Structural Analysis and Design at the University of Salerno, Italy. His scientific interests include experimental and theoretical activities intended at investigating the behavior of materials (e.g. sustainable concrete, composite materials, masonry, etc.) and structures (RC frames, steel-concrete composite systems, etc.) under various loading conditions. Earthquake engineering, mainly dealing with the seismic assessment and retrofitting of existing structures, is another subject of interest in his scientific work.

Joaquim A.O. Barros is Full Professor of the Department of Civil Engineering of Minho University, header of the Structural Concrete Research Group of ISISE. His research interests include structural strengthening, composite materials, fiber reinforced concrete and the development of constitutive models for the simulation of the behavior of cement based and polymer based materials, and their implementation in software based on the finite element method. He is the co-founder of the FEMIX FEM-based computer program for advanced structural analysis.

Guillermo Etse is a Full Professor at the Faculty of Exact Sciences and Technology, University of Tucuman, Argentina, and an Independent Researcher at the Argentinean Council for Scientific Researches. His research field covers the constitutive modeling for cohesive-frictional porous materials like concrete and soils, the formulation of mathematical indicators for ductile and localized/brittle failure modes of material theories, and the FE application for computational simulations of failure processes in concrete and soils related boundary value problems.

ACI member Liberato Ferrara is Associate Professor of Structural Analysis and Design at Politecnico di Milano, where he received his MSc in Building Engineering and his $\mathrm{PhD}$ in Structural Engineering. He has been Fulbright scholar at ACBM-Northwestern University. He is chair of ACI-TC 544-C (FRC-testing) and member of ACI 237 (SCC), 238 (workability), 239 (UHPC) and 241 (Nanotechnology of concrete). His research interests include mechanical properties, durability and structural applications of advanced cement based materials.

ACI member Paula Folino is Associate Professor in the field of Reinforced Concrete Structures and Head of the Department of Constructions and Structures at the Faculty of Engineering of the University of Buenos Aires (FIUBA), Argentina. Her research interests include structural engineering, material science, computational mechanics and constitutive modeling.

Eduardus A.B. Koenders is Professor and head of the Institute for Construction and Building Materials, Faculty of Civil and Environmental Engineering, Technical University of Darmstadt, Germany. His research interests include multi-scale modeling of hydration and moisture transport, sustainable and durable materials, recycled aggregates and energy saving material concepts for construction. He is RILEM member and chairman of the RILEM EAC MMC course on multi-scale modeling of concrete.

Romildo Dias Toledo Filho is a Full Professor in the Civil Engineering Department of the Universidade Federal do Rio de Janeiro (COPPE/UFRJ), Brazil. He is the head of the Center for Sustainable Materials and Technologies of COPPE/UFRJ. He is member of the RILEM TC 240-FDS, TC 225-SAP and TC 254-CMS. His research interests include fiber-reinforced concrete, innovative cement-based materials, concrete mix design, creep, shrinkage and durability of concrete, oil-well slurries and concrete at high temperature. 


\section{INTRODUCTION}

Environmental issues are getting more and more relevant in the construction sector, as well as in other industrial branches and human activities. Due to obvious reasons, construction and demolition waste and other industrial by-products may be employed for obtaining recycled concrete constituents. For instance, recycled concrete aggregates (RCA) can be produced from existing concrete members that result from either industrial processes (i.e., precast structures) or demolitions of existing structures as a whole. In the latter case, concrete is not the only component of waste, as demolition rubbles of RC buildings also contain other materials, such as steel bars, masonry bricks, wood, plastics and so on. Moreover, waste resulting from industrial processes other than the building industry could, therefore, be efficiently disposed as concrete aggregates, as well. Sometimes similar industrial processes could even produce waste (i.e., mainly made out of either plastics or metals) that may efficiently be employed as dispersed reinforcement, by resulting a class of cement based materials designated as Fiber-Reinforced Concretes (FRC) or, more generally, Fiber-Reinforced Cementitious Composites (FRCCs). In such cases, the technological aspects of assuring proper distribution of these reinforcements, the physical and chemical issues concerning the compatibility between the fibers and cementitious matrix, the durability of the resulting material, as well as its mechanical performance, should be deeply investigated. A further environmentally-friendly and cost-effective solution for producing FRCCs can be achieved by applying natural fibers as a reinforcement system. The characterization of the key physical and mechanical properties of these novel class of cementitious materials made partly from the aforementioned replacements of recycled and natural constituents is the main goal of the EnCoRe Project (www.encore-fp7.unisa.it), a EU-funded initiative outlined in this article. Three objectives are addressed:

Objective 1) predicting the physical and mechanical performance of concrete with recycled aggregates;

Objective 2) understanding the possible contribution of recycled fibers used as a dispersed reinforcement in concrete matrices;

Objective 3) demonstrating the feasibility and possible applications of using natural fibers as a reinforcement in cementitious composites.

The objectives were pursued through three main sequential tasks (namely, experimental activities, theoretical/numerical modeling and guideline formulation) whose main findings are summarized in the following sections.

\section{EXPERIMENTAL INVESTIGATION}

Experimental tests were carried out for investigating the physical properties and the mechanical behavior of the three materials mentioned within the objectives of the EnCoRe Project.

\section{Recycled Aggregate Concrete (RAC)}

The activities developed as part of the EnCoRe Project were intended at investigating the mechanical behavior of concrete with recycled constituents. This specific class of materials would otherwise be considered as an ordinary waste with a high economic and environmental value, and with significant costs for regular disposal. Therefore, particular attention was paid to the possibility of partially replacing both aggregates and cement with recycled constituents, such as Recycled Concrete Aggregates (RCA) and/or Fly Ash (FA) ${ }^{10}$. Fly-ash is a fine, glass-like powder recovered as a waste from the gases created by coal-firing electric power generators. Using FA in concretes provides a double benefit: firstly, it reduces the total amount of industrial waste and, secondly, it reduces the production of Portland cement with its significant atmospheric emissions of $\mathrm{CO}_{2}$. The use of both FA and RCA in concrete production is supposed to significantly improve the mechanical properties of RCA, and making them more comparable with those concretes made with cements and virgin aggregates. Starting with an ordinary concrete mixture as a reference, three groups made of four different concrete mixtures were designed and produced to investigate the effect of partial cement replacement by an "equivalent" amount of FA as a reactive pozzolan. In addition, the four mixtures per group are also characterized by different recycled-to-total aggregate replacement ratios. Table 1 provides an overview of the thirteen mixtures considered in the study. The first group are four RAC mixtures were $80 \mathrm{~kg} / \mathrm{m}^{3}\left(4.99 \mathrm{lb} / \mathrm{ft}^{3}\right)$ FA was added and were $30 \mathrm{~kg} / \mathrm{m}^{3}\left(1.87 \mathrm{lb} / \mathrm{ft}^{3}\right)$ was considered to act as a replacement for the Portland cement once compared with the reference mixture. The second group has $220 \mathrm{~kg} / \mathrm{m}^{3}\left(13.73 \mathrm{lb} / \mathrm{ft}^{3}\right)$ FA added of which also $30 \mathrm{~kg} / \mathrm{m}^{3}\left(1.87 \mathrm{lb} / \mathrm{ft}^{3}\right)$ is considered to act as a replacement for Portland cement and the remaining part to act as a filler. Finally, the third group was prepared with even a higher FA content, i.e. $255 \mathrm{~kg} / \mathrm{m}^{3}\left(15.92 \mathrm{lb} / \mathrm{ft}^{3}\right)$, which was more than a complete replacement of the Portland cement of the reference mixture, and was well beyond the limits allowed by current regulations.

All mixtures were designed to obtain a minimum slump of $160 \mathrm{~mm}(6.30 \mathrm{in})$ and, although this requirement was achieved for all of them, a significant reduction in workability was observed as a result of the recycled aggregates addition, whereas the addition of the large amounts of FA partly compensate for this reduction in workability, probably due to the rounded shape of the particles. This synergetic effect is even more apparent once considering the compressive strength in the hardened state (Figure 1). From this, the mean values of the 
compressive strength were evaluated by testing several cubes prepared from the thirteen concrete mixes under consideration. Tests have been performed for different curing times, ranging from 2 to 90 days.

Figure 1 highlights the time evolution of compressive strength measured for samples made with mix "LN" - i.e. the natural aggregate concrete with the lowest amount of FA - which turns out to be very close to the reference one (mix "N"). On the other hand, the experimental results also show that partial replacement of natural aggregates with recycled ones leads to a substantial reduction in the compressive strength of the concretes. Particularly, a closer look at experimental results from the RCA specimens showed the following observations:

a) a progressive reduction of the concrete compressive strength has occurred with the increase of the percentage of recycled aggregates in the mix (compare the strength values obtained for the three mixtures "LR", the three "MR" and the three "HR" reported in the bar diagram in Figure 1);

b) acceptable performances have been obtained for curing times longer than 28 days, in case of RCA $=60 \%$, and when high amounts of FA have been added to the mix (see strength values of mixes "MR60" and "HR60");

c) replacing $30 \%$ of NAs with RCAs together with the addition of a low amounts of FA (viz. mix "LR30") led to a concrete compressive strength comparable to the reference mix (i.e. the mix "N"); in fact, regardless the curing times, the difference between the mean strength values of these two types of concretes did not exceed $10 \%$;

d) the concrete strength of those mixtures with a high content of RCA could be improved by partially replacing the finest aggregate fractions with FA (compare the strengths of RCA100\% samples, i.e. mixes "LR100", "MR100" and "HR100").

Empirical evidence from the briefly reported experimental program confirms that recycled aggregates have a significant influence on the mechanical behavior of RCA. The main reason for this is the aggregates from recycled concretes show a significantly higher porosity with respect to ordinary aggregates. Such a higher porosity does not only result in a more porous (and weaker) structure of the concrete matrix, but it may also cause a change in the cement hydration reaction, as it results in a potentially higher water content in the mix. Depending on the absorption capacity, a higher moisture content may affect the overall hydration process. This very fundamental modification was thoroughly investigated by observing the time evolution of the degree of hydration under adiabatic conditions obtained for concretes with ordinary aggregates and recycled ones. Particularly, a significant influence of the altered moisture condition due to the aggregates (either dry or soaked) was observed on the time evolution of the hydration reaction, which is basically unaffected by this aspect in the case of ordinary concrete ${ }^{12,13}$.

Finally, results obtained from the experimental tests clearly demonstrate the feasibility of structural concrete with recycled constituent. Particularly, a synergetic effect of combining recycled aggregates with FA clearly emerged. Experimental results demonstrate that the limitation imposed by current codes and regulations in terms of replacement ratios could be reconsidered, when considering the almost identical performance for the mechanical performance of RCA mixtures. For this, a deeper understanding of the fundamental phenomena that drive the hydration process of RCAs is essential and will lead to an extension of the current level of knowledge on such materials, which so far have been mainly investigated under a merely empirical standpoint. The durability issues on RCAs with relatively high percentage of cement replaced by FA should be also deeply investigated.

\section{Recycled Steel Fiber Reinforced Cementitious Composites (RSFRCC)}

The increasing amount of used tires constitutes a serious threat to the environment, as well as to the human health. Moreover, based on the "Council Directive 1999/31/EC" of the European Commission on the Landfill of Waste, "whole tires" could no longer be landfilled and, since July 2006, such regulations must both be applied to either "whole" or "shredded" tires. Therefore, there are strong motivations for recycling and reusing such waste materials. The recycling processes of waste tires mainly consist of separating the internal steel reinforcement from the rubber layer. Figure 2 shows an example of steel fibers obtained from processing outof-use tires, and, as a result of this process, they appear in a curling and twisted form, with their length and diameter quite irregular.

These Recycled-Steel fibers (RSFs) can constitute a partial or total replacement of industrial fibers (ISF), or conventional steel bars, or even a secondary reinforcement for the enhancement of the crack control, leading a material herein designated by Fiber-Reinforced Cementitious Composites (FRCCs). An extensive experimental study was carried out as part of the EnCoRe project for investigating the flexural response (in three-point notched beam bending tests) of FRCC with RSFs of volume fraction variable between 45 and $90 \mathrm{~kg} / \mathrm{m}^{3}(2.81$ and $5.62 \mathrm{lb} / \mathrm{ft}^{3}$ ). Figure 3 shows that the deflection hardening phase registered in the ISFRC specimens (from crack initiation up to flexural tensile strength) was not developed in the RSFRC specimens. This indicates that fiber bridging mechanisms across the crack surfaces for relatively small crack width levels are not effective in the RSF due to the geometry and surface characteristics of these fibers. However, in the post-peak stage the 
RSFRC specimens have almost retained the maximum flexural tensile strength up to the ultimate crack width recorded in the executed tests $(3.5 \mathrm{~mm})$.

The use of RSF $\left(60 \mathrm{~kg} / \mathrm{m}^{3}\right.$, or $\left.3.75 \mathrm{lb} / \mathrm{ft}^{3}\right)$ as a shear reinforcement of $\mathrm{RC}$ beams was investigated by executing the exploratory experimental program represented in Figure $4 \mathbf{a}^{14}$. The relationship between the applied load and the deflection at the loaded section of the tested series of beams is represented in Figure $\mathbf{4 b}$. On the basis of the obtained results it was observed that the ratio of the shear capacity obtained experimentally to that calculated using RILEM and fib guidelines decreased with the increase of the beam web thickness, which indicates that both formulations require some enhancements for better consider the geometry of the beam in order to more accurately simulate the fiber orientation and distribution on the effectiveness of the fiber reinforcement mechanisms. These tests were numerically simulated by performing material nonlinear analysis with a smeared crack model under the framework of the finite element method, where the fracture mode I parameters of the crack constitutive model was determined by executing inverse analysis with the force-CMOD data registered in three-point notched beam bending tests. By using this model and adopting a plain concrete of the same strength class of the RSFRC used in the tested RC beams, it was verified that $\left(90 \mathrm{Kg} / \mathrm{m}^{3}\right.$, or $\left.5.62 \mathrm{lb} / \mathrm{ft}^{3}\right)$ of RSF provided an increase of $95 \%, 81 \%$ and $71 \%$ in terms of shear capacity of the beams with a web's thickness of 70,110 and $150 \mathrm{~mm}$, respectively, when the shear capacity of the reference beam (plain concrete with the same flexural reinforcing ratio) is considered for comparison purpose. This is a good indicator of the potentialities of RSFRC for the shear reinforcement of concrete structures.

\section{Natural Fiber Reinforced Cementitious Composites (NFRCC)}

Although natural fibers can be produced from a large variety of plants, in the EnCoRe Project focus was on sisal fibers that have been extensively studied at LabEST/UFRJ over the last decades. Sisal fibers are extracted from the leaves of sisal plant (Agave sisalana) showing long fiber bundles. A sisal plant produces between 200 and 250 leaves before flowering, each of which contains approximately 700-1400 fiber bundles with a length of about $0.5-1.0 \mathrm{~m}$ (1.64-3.28 ft). The sisal leaf consists of a sandwich structure composed of approximately $4 \%$ fiber, $1 \%$ cuticle, $8 \%$ dry matter, and $87 \%$ water. The equivalent diameter of sisal fibers is around $200 \mu \mathrm{m}(7.87$ mil) and the cross-section is rarely circular but usually has an "arch" or "horseshoe" shape' (Figure 5).

The chemical composition of the sisal fiber comprehends approximately $54-66 \%$ cellulose, $12-17 \%$ hemicellulose, $7-14 \%$ lignin, $1 \%$ pectin and $1-7 \%$ ash.

The use of natural fibers, in combination with steel fibers to produce High Performance Fiber Reinforced Cementitious Composites, was investigated as part of the EnCoRe Project. Due to the large size differences between steel and natural fibers different combinations of hybridization with steel fibers were adopted. In order to widen the investigation, a composite with raw sisal fibers, hybridized with either cellulose nanopulp, microcrystalline cellulose powder and eucalyptus microfibers was studied as well ${ }^{2}$.

The influence of pre-saturation of raw sisal fibers was also investigated. Because of their highly hydrophilic nature and porous microstructure, natural fibers can absorb water as well. This can happen either during the mixing process or through dedicated pre-saturation. This water, accumulated in the porous natural fibers may also be released during cracking or at damaged locations where it may reactivate hydration reactions and initiating a delayed self-healing processes for "repairing" these cracks or damage ${ }^{6}$ (Figure 6).

\section{THEORETICAL MODELING}

Theoretical models were developed with the aim of interpreting the experimentally observed behavior of the eco-friendly materials considered as part of the EnCoRe Project.

The fundamental influence of RCA on the time development of the cement hydration reactions in RAC was firstly addressed by formulating a phenomenological model based on the Theory of Heat Transfer through solid media and the Arrhenius principle of time-temperature equivalence ${ }^{11}$. On the one hand, based on temperature measurements in semi-adiabatic conditions, the model is capable of back-simulating the time evolution (i.e. in terms of degree of hydration) of the same reaction as it would develop in ideal adiabatic conditions. On the other hand, once the adiabatic curve is determined, the model can simulate the cement hydration reaction developing in the same concrete mixtures in different thermal boundary conditions, such as the isothermal ones, usually adopted in standard concrete curing. Figure 7 shows the three time evolution of the cement reactions developing in a mixture with $60 \%$ aggregate replacement (initially oven-dried) cured in adiabatic and iso-thermal conditions, as derived by the model on the basis of the measurements in semi-adiabatic conditions. The model was employed for investigating the effect of the nominal water-cement ratio, the initial moisture condition of RCAs and the recycled-to-total coarse aggregate replacement ratio on the resulting cement hydration reaction and, hence, the obtained compressive strength ${ }^{9}$.

Further models were developed for simulating the mechanical behavior of RAC. Particularly, both a formulation based on continuous Leon-Drucker-Prager approach and an alternative one based on the Performance Dependent Model (PDM), originally proposed for concrete of variable quality ${ }^{7}$, were developed. The latter, originally formulated with the aim of reproducing the specific features of concrete behavior depending on its 
quality defined by both the compressive strength and a performance index based on the water binder ratio (and, then, unify the theories available for ordinary and high-strength concretes), was generalized therein to simulate the mechanical behavior and the failure modes observed for $\mathrm{RAC}^{8}$.

The influence of RSFs was intended at predicting the decay induced in terms of mechanical performance as a function of the total amount and the specific fraction of recycled fibers. The formulation of a mechanical model based on a meso-scale approach based on the explicit simulation of the behavior of the key constituents of FRCC (i.e. aggregates, cement paste, fibers) and their interaction in terms of crack-bridging and dowel effects was firstly proposed, based on the experimental results obtained from pull-out tests carried out on single fibers embedded in cementitious matrices. Then, a model based on the cracked hinge kinematics was also proposed through an appropriate fracture-based formulation, with the aim of simulating the crack-bridging mechanisms of steel fibers. Figure 8 shows the comparison between the experimental results and the corresponding numerical simulation: it highlights the fairly good capability of the latter to reproduce the former.

Finally, the modeling of self-healing phenomenon has also been tackled, both from a macro-mechanical point of view and from a micro-mechanical one, with reference to plain concrete ${ }^{6}$. As for the first approach, an interface model based on fracture energy concepts was developed which takes into account the self-healing mechanism through an internal porosity evolution law. The proposed interface formulation is particularly appropriated for predicting the behavior of mortar-to-mortar interfaces in the framework of mesoscopic analysis of self-healing phenomena, which provides a very effective approach for the study of this problem. As for the second approach, the self-healing effects, in particular delayed cement hydration, was incorporated into the SMM by means of a self-healing function which depends on crack opening, degree of hydration, moisture content and temperature ${ }^{3}$. The performance of both approaches in capturing the recovery of load bearing capacity of a pre-cracked concrete specimen after healing is shown in Figure 9.

\section{GUIDELINES FORMULATION}

A series of guidelines were proposed for the production and the structural application of the materials mentioned under considerations. Far from being a complete code of standards on these subjects ${ }^{4}$, these documents were rather intended as a "Model Code" or, better, as an annex to the recent Model Code for Structural Concrete $2010^{5}$, specifically addressing the peculiar features of RAC as a structural material.

Being inspired to the aforementioned Model Code and to its previous versions, it is worth clarifying what these document are and what they are not. They are not structural building codes and, then, they cannot be employed in designing structures made of RAC: in fact, several aspects reported therein are only addressed from a "conceptual" stand-point and further studies are still needed to close the gap of knowledge between such conceptual formulation and a consistent operational framework complying with the bases of design principles defined in EN 1990 (2005). Conversely, they were an attempt to propose a possible basis for a future Code of Standard which either includes or specifically addresses the structural design of structures made of RAC.

Therefore, the present prototypical guidelines aim to be fully consistent with the recent Model Code for Concrete Structures 2010 whose scope is limited to "structural concrete with normal and lightweight aggregates, composed and compacted so as to retain no appreciable amount of entrapped air other than intentionally entrained air"5. In spite of this explicitly declared limitation, the Model Code 2010 introduces in structural design of concrete structures some "performance requirements for sustainability" which, in principle, aims "to reduce impacts on the environment, society and economy by evaluating and verifying the performance of concrete, concrete components and structures" 5.

As a matter of fact, the commentary of Model Code 2010 refers to "green concrete (also known as sustainable or ecological concrete)" as a possible solution for "having a significantly improved sustainability compared to ordinary structural concrete" and recognises that "so far, no generally accepted limiting values and benchmark exists"5. Moreover, it reports the following description of this kind of material which will be retained as a reference definition throughout this guideline: "green concrete may be produced, for example, by the replacement of cement by chemically reactive or inert fine materials, by a significant reduction of the total binder content and also by the replacement of the aggregates, for example, with recycled concrete" 5 .

Particularly, as regards the use of recycled aggregates as concrete constituents, the proposed document firstly focused on the characterisation of RCAs that are the main character in the play and need specific provisions to be duly described, especially with respect to the main features potentially affecting the resulting concrete properties. Considering that recycled coarse aggregates obtained from the crushing of waste concrete present greater porosity than natural ones due to the presence of a thin layer of cement paste that remains adhered to the original aggregate surface after the crushing process, the following quality index QI was defined for RCAs:

$\mathrm{QI}^{\mathrm{RAC}}=\frac{\mathrm{Abs}^{\mathrm{NAC}}}{\mathrm{Abs}^{\mathrm{RAC}}}$ 
where $\mathrm{Abs}^{\mathrm{RCA}}$ and $\mathrm{Abs}^{\mathrm{RCA}}$ are the 24-hour water absorption capacity of natural and recycled aggregates, respectively, for a given size fraction. It is easy to understand that the close $\mathrm{QI}^{\mathrm{RAC}}$ is to the unit, the lower is the decay in mechanical properties of RAC induced by the presence of RCA for a given replacement ratio R, meaning that the RCAs present almost the same physical properties than the natural ones. The values of $\mathrm{QI}^{\mathrm{RAC}}$, as well as the replacement ratio $\mathrm{R}$ and the initial moisture condition of coarse aggregates are the three "factors" that have to be taken into account to a generalised mix-design rule that was also proposed as part of these guidelines.

Finally, it is worth highlighting that no section- or member-level design relationship were developed in these document for determining the response of structural members made of RAC: all formulations proposed by Model Code 2010 were deemed valid for such members, provided that the constituents are characterised and the material properties are defined according to the specific provisions reported herein.

\section{CONCLUSIONS}

The paper provided an overview of the main findings come out of the EU funded project EnCoRe. A new bulk of knowledge was produced and is now available to be transferred to both concrete technologists and practicing civil engineers: it is expected to significantly "greening" the concrete industry.

\section{ACKNOWLEDGMENTS}

The authors wish to acknowledge the support to the networking activities provided by "EnCoRe" project (www.encore-fp7.unisa.it) (FP7-PEOPLE-2011-IRSES, n. 295283) funded by the European Union as part of the 7th Framework Programme for Research and Innovation.

\section{REFERENCES}

1. Almeida Melo Filho J., Andrade Silva F., and Toledo Filho R.D., "Degradation kinetics and aging mechanisms on sisal fiber cement composite systems", Cement and Concrete Composites, vol. 40, 2013, pp. 3039.

2. Alves Fidelis M.E., Vitorino Castro Pereira T., Fonseca Martins Gomes O., Andrade Silva F., and Toledo Filho R.D., "The effect of fiber morphology on the tensile strength of natural fibers", Journal of Materials Research and Technology, Vol. 2, No. 2, 2013, pp. 149-157.

3. di Luzio G., and Cusatis G., "Solidification micro-prestress microplane (smm) theory for concrete at early age: Theory, validation and application", International Journal of Solids and Structures, Vol. 50, No. 6, 2013, pp. 957-975.

4. EN 1990: Eurocode - Basis of structural design, 2005.

5. fib, fédération international du beton, "Model Code for Concrete Structures 2010", Ernst \& Sohn Verlag, 2013, Berlin (Germany)

6. Ferrara L., Krelani V., and Carsana M. "A fracture testing based approach to assess the effects of crack healing on the recovery of mechanical properties of concrete with and without crystalline admixtures", Construction and Building Materials, Vol. 68, 2014, pp. 515-531.

7. Folino P., Etse G., Will A., "Performance Dependent Failure Criterion for Normal-and High-Strength Concretes", ASCE Journal of engineering mechanics, Vol.135, No. 12, pp. 1393-1409.

8. Folino P., Xargay H., "Recycled aggregate concrete-Mechanical behavior under uniaxial and triaxial compression", Construction and Building Materials, Vol. 56, 2014, pp. 21-31

9. Koenders E.A.B., Pepe M., and Martinelli E., "Compressive strength and hydration processes of concrete with recycled aggregates", Cement and Concrete Research, Vol. 56, 2013, pp. 203-212.

10. Lima C., Caggiano A., Faella C., Martinelli E., Pepe M., and Realfonzo R., "Physical properties and mechanical behaviour of concrete made with recycled aggregates and fly ash", Construction and Building Materials, Vol. 47, pp. 547-559.

11.Martinelli E., Koenders E.A.B., and Caggiano A., "A numerical recipe for modelling hydration and heat flow in hardening concrete", Cement and Concrete Composites, Vol. 40, 2013, pp. 48-58.

12. Pepe M., Toledo Filho R.D., Koenders E.A.B, Martinelli E., "Alternative processing procedures for recycled aggregates in structural concrete", Construction and Building Materials, Vol. 69, 2014, pp 124-132.

13. Toledo Filho R.D., Koenders E.A.B., Pepe M., Cordeiro G.C., Fairbairn E., and Martinelli E., "Rio 2016 sustainable construction commitments lead to new developments in recycled aggregate concrete", Proceedings of the Institution of Civil Engineers. Civil engineering, Vol. 166, No. 6, 2013, 28-35.

14. Zamanzadeh Z., Lourenço L., and Barros J., "Recycled Steel Fibre Reinforced Concrete failing in bending and in shear", Construction and Building Materials, Vol. 85, 2015, pp. 195-207. 
TABLES AND FIGURES

2 Table 1-Description of the concrete mixture composition for RAC

\begin{tabular}{|c|c|c|c|c|c|c|c|c|c|c|c|c|c|c|c|}
\hline \multirow{2}{*}{ Mix } & $\mathbf{C}$ & & \multirow{2}{*}{ FA/C } & \multirow{2}{*}{$\begin{array}{r}\text { RCA } \\
{[\%]}\end{array}$} & \multirow{2}{*}{\multicolumn{2}{|c|}{$\begin{array}{l}\text { w Wadd } \\
{\left[\mathrm{kg} / \mathrm{m}^{3}\right]}\end{array}$}} & \multicolumn{4}{|c|}{$\mathrm{NA}\left[\mathrm{kg} / \mathrm{m}^{3}\right]$} & \multicolumn{4}{|c|}{$\mathrm{RCA}\left[\mathrm{kg} / \mathrm{m}^{3}\right]$} & \multirow{2}{*}{$\mathbf{W}_{\text {tot }} / \mathbf{b}_{0}$} \\
\hline & \multicolumn{2}{|c|}{$\left[\mathrm{kg} / \mathrm{m}^{3}\right]$} & & & & & N3 & $\mathbf{N} 2$ & N1 & Sand & N3 & N2 & N1 & Sand & \\
\hline $\mathbf{N}$ & 280 & 0 & 0 & $\mathbf{0}$ & 150 & 14.02 & 505 & 470 & 165 & 830 & - & - & - & - & 0.59 \\
\hline $\mathbf{L N}$ & 250 & 80 & 0.32 & $\mathbf{0}$ & 150 & 14.02 & 505 & 470 & 165 & 750 & - & - & - & - & 0.58 \\
\hline LR30 & 250 & 80 & 0.32 & 30 & 150 & 21.86 & - & 408 & 165 & 750 & 445 & 55 & - & - & 0.61 \\
\hline LR60 & 250 & 80 & 0.32 & 60 & 150 & 38.16 & - & - & - & 750 & 445 & 415 & 145 & - & 0.67 \\
\hline LR100 & 250 & 80 & 0.32 & 100 & 150 & 109.65 & - & - & - & - & 445 & 415 & 145 & 660 & 0.92 \\
\hline MN & 250 & 220 & 0.88 & 0 & 150 & 11.28 & 545 & 490 & 170 & 500 & - & - & - & - & 0.48 \\
\hline MR30 & 250 & 220 & 0.88 & 30 & 150 & 17.85 & 35 & 490 & 170 & 500 & 450 & - & - & - & 0.50 \\
\hline MR60 & 250 & 220 & 0.88 & 60 & 150 & 28.99 & - & - & 185 & 500 & 455 & 450 & - & - & 0.53 \\
\hline MR100 & 250 & 220 & 0.88 & 100 & 150 & 98.84 & - & - & - & - & 400 & 375 & 130 & 595 & 0.74 \\
\hline HN & 200 & 255 & 1.27 & $\mathbf{0}$ & 150 & 11.28 & 545 & 490 & 170 & 500 & - & - & - & - & 0.53 \\
\hline HR30 & 200 & 255 & 1.27 & 30 & 150 & 17.85 & 35 & 490 & 170 & 500 & 450 & - & - & - & 0.56 \\
\hline HR60 & 200 & 255 & 1.27 & 60 & 150 & 28.68 & - & - & 175 & 500 & 455 & 445 & - & - & 0.59 \\
\hline HR100 & 200 & 255 & 1.27 & 100 & 150 & 98.84 & - & - & - & - & 400 & 375 & 130 & 595 & 0.82 \\
\hline
\end{tabular}

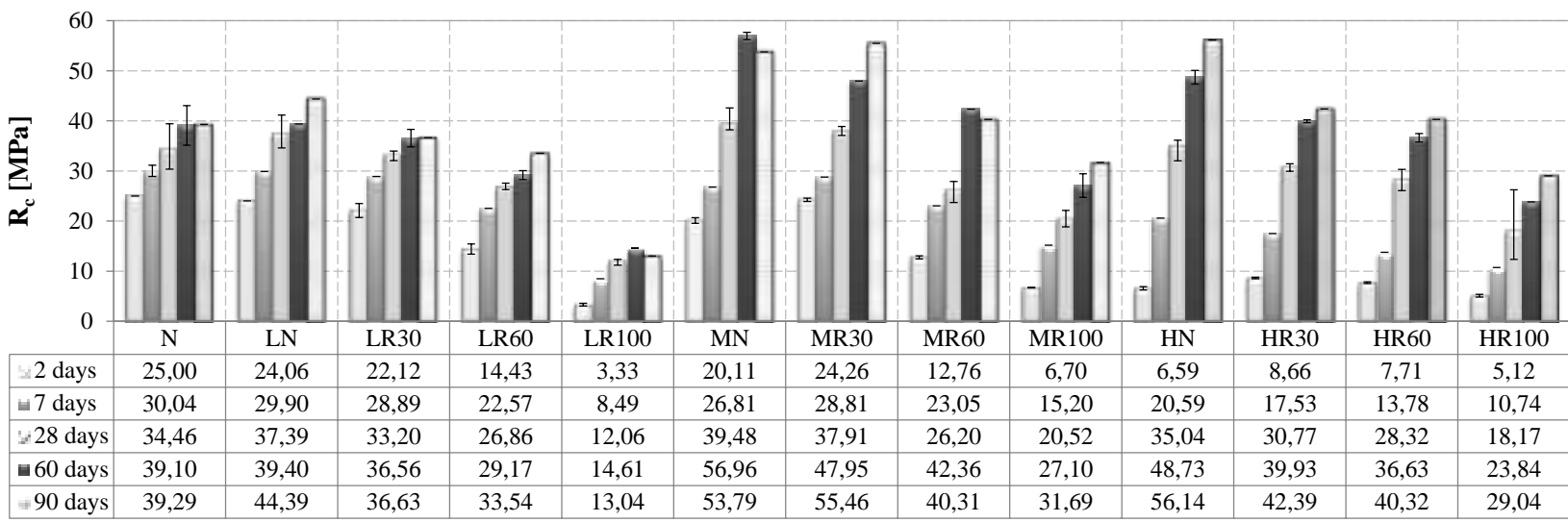

Figure 1- Time evolution of the cubic compressive strength $(1 \mathrm{MPa}=145.04 \mathrm{psi})$

8

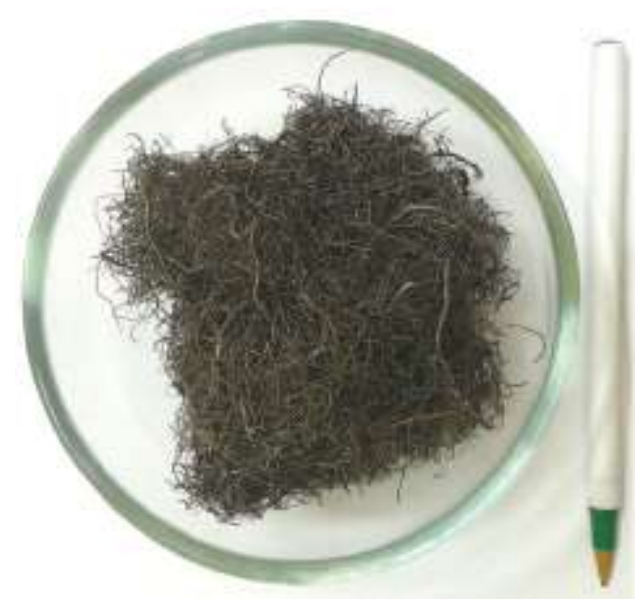

Figure 2- A sample of recycled steel fibers. 

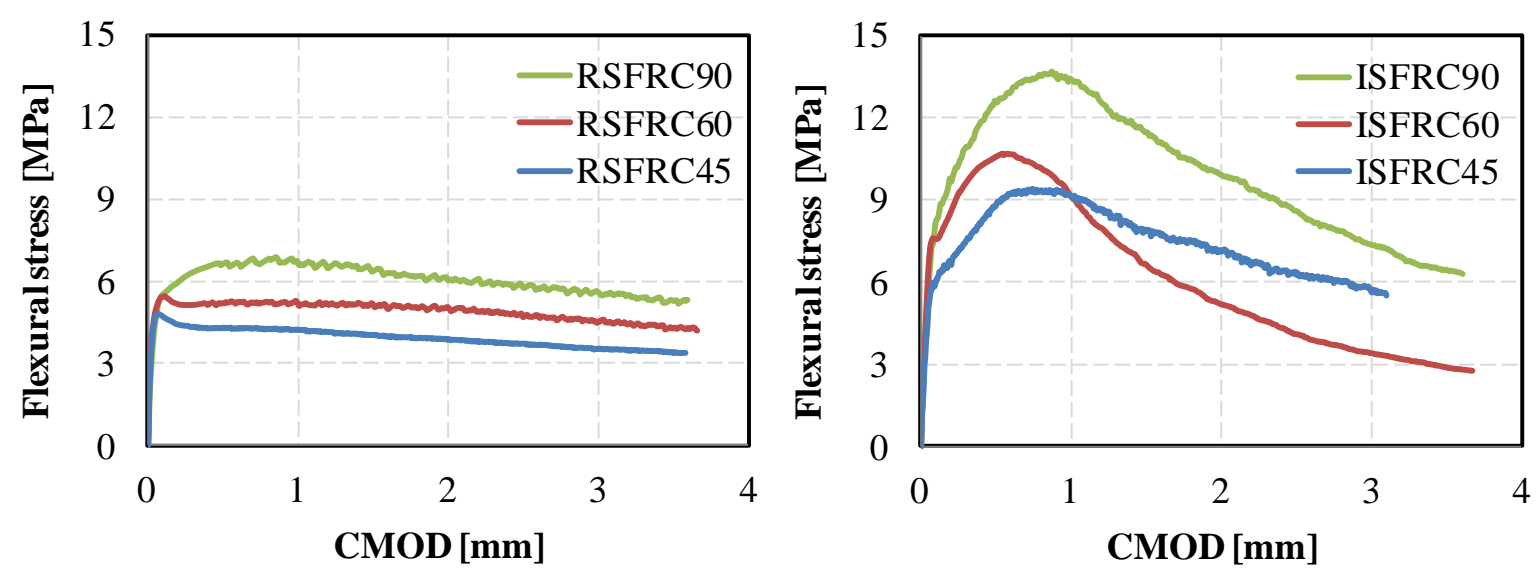

Figure 3- Flexural response of cementitious composites with RSFs and ISFs

$(1 \mathrm{MPa}=145.04 \mathrm{psi} ; 1 \mathrm{~mm}=0.3937 \mathrm{in})$

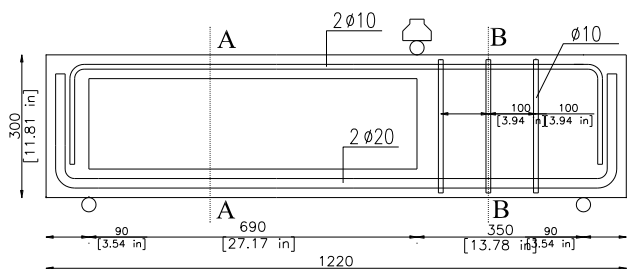

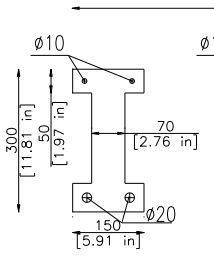

$\underline{\text { Section A-A }}$

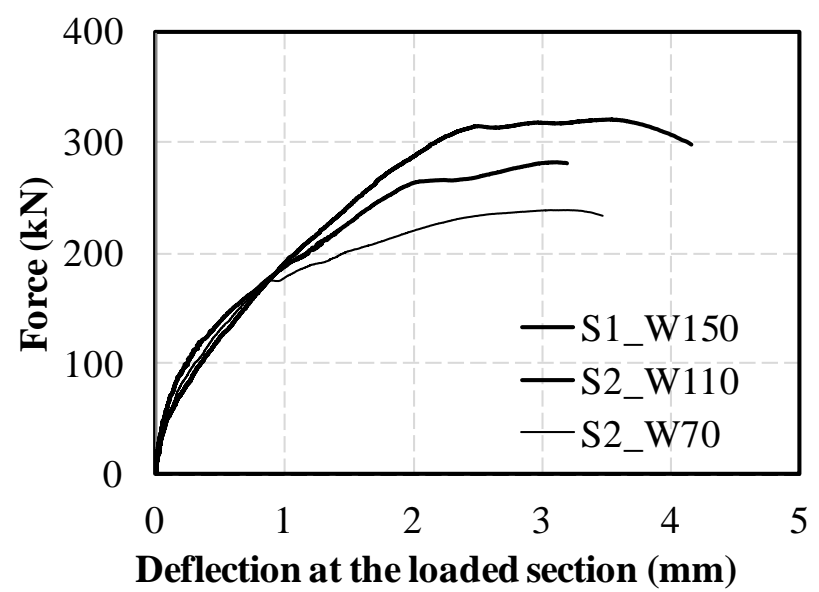

Figure 4- RSFRC beam tests: geometric properties and results of the bending tests (1 $\mathrm{kN}=224.73 \mathrm{lb} ; 1 \mathrm{~mm}=0.3937 \mathrm{in})$.

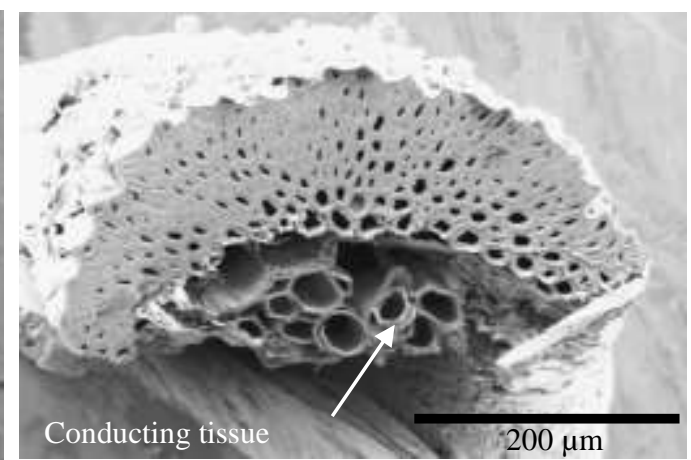

b) Sisal: Arch shape fiber

Figure 5- Natural fibers considered in the EnCoRe Project $(200 \mathrm{~mm}=0.00787$ in $)$ 

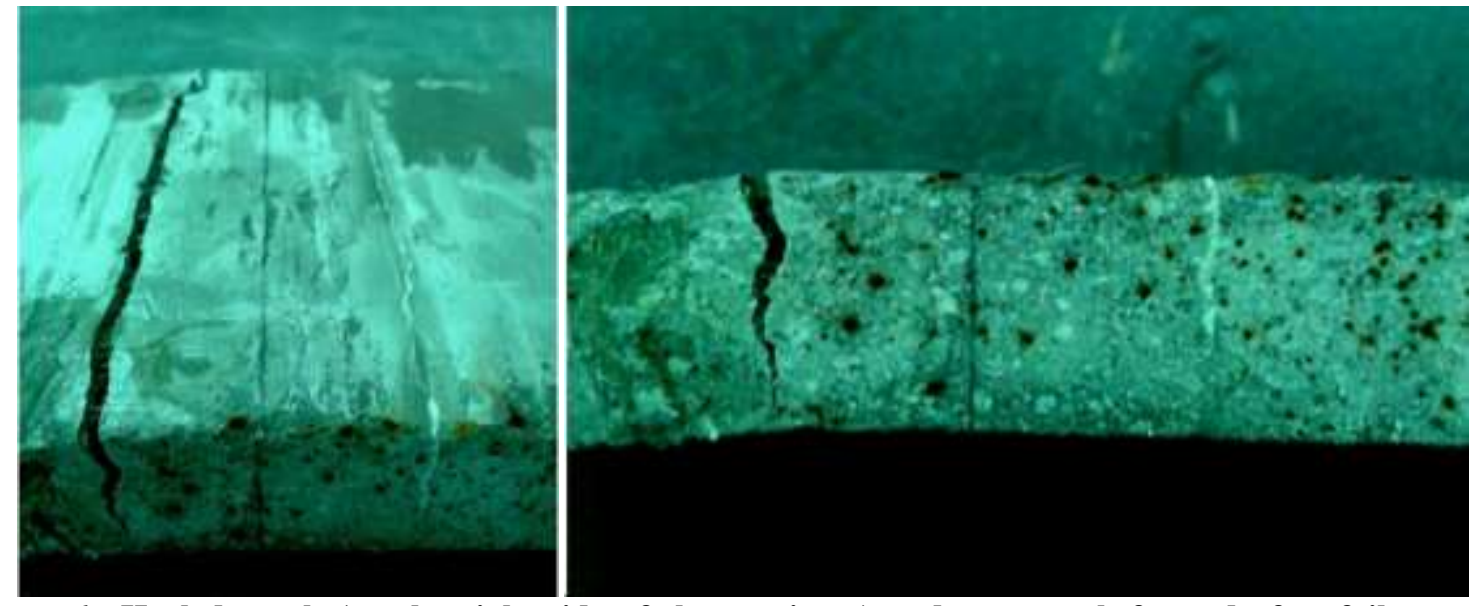

Figure 6- Healed crack (on the right side of the specimen) and new crack formed after failure posthealing tests in HPFRCC reinforced with steel and sisal fibers.

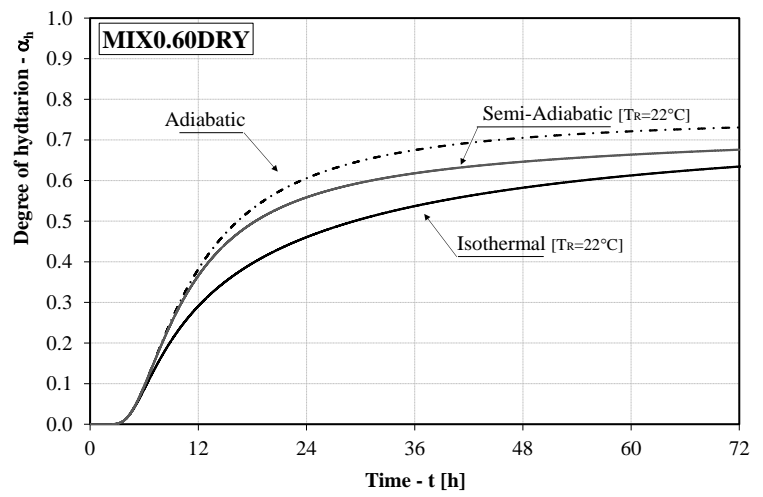

Figure 7-Simulating the hydration reaction in RAC

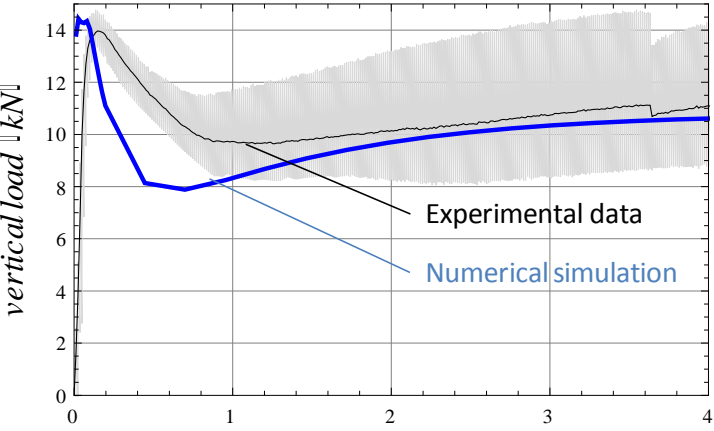

CTODm $\|\mathrm{mm}\|$

a) RSFRC 0-05

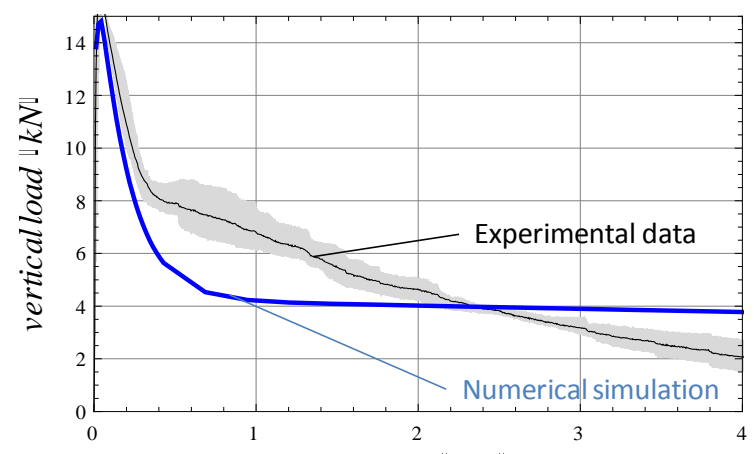

CTODm $\|\mathrm{mm}\|$

b) RSFRC 100-05

Figure 8- Macroscopic modeling of the flexural response of FRCC with ISFs and RSFs (1 $\mathbf{m m}=0.3937 \mathrm{in})$
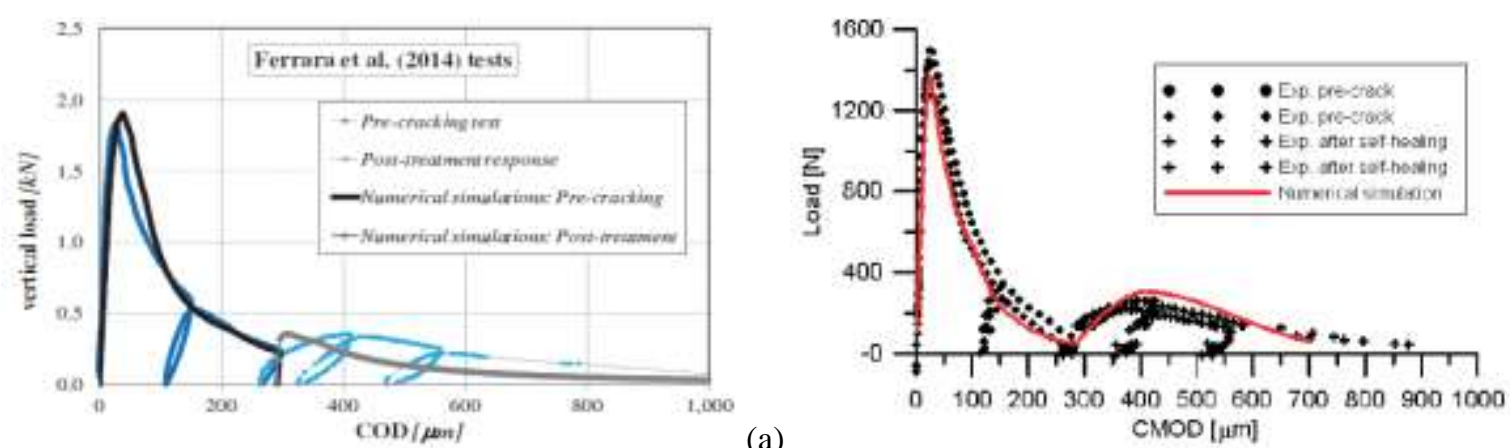

(a)

Figure 9- Modeling self healing in plain concrete: zero-thickness interface model (a) and SMM model (b) $(1 \mathrm{kN}=224.73 \mathrm{lb} ; 1 \mu \mathrm{m}=0.0003937 \mathrm{in})$ 